\title{
Study on nano-structured hydroxyapatite/zirconia stabilized yttria on healing of articular cartilage defect in rabbit ${ }^{1}$
}

\author{
Amir Sotoudeh", Amirali Jahanshahi", Mohammad Ashrafzadeh Takhtfooladi"II, Ali Bazazan" ${ }^{\text {IV }}$ Amin Ganjaliv, Maryam \\ Pourramezani Harati ${ }^{\mathrm{VI}}$

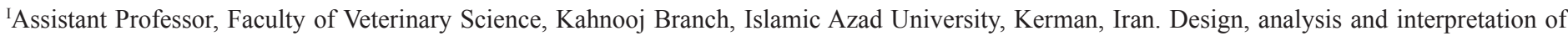 \\ data; manuscript writing.

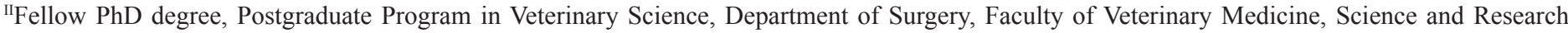 \\ Branch, Islamic Azad University, Tehran, Iran. Design, collection and processing of study information.

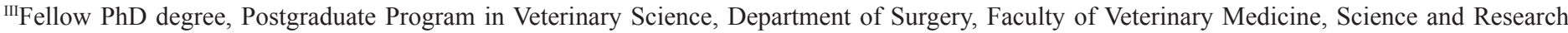 \\ Branch, Islamic Azad University, Tehran, Iran. Technical procedures, collection and processing of study information, analysis and interpretation of \\ data, statistical analysis. \\ ${ }^{\mathrm{IV}}$ Assistant Professor, Faculty of Veterinary Science, Garmsar Branch, Islamic Azad University, Semnan, Iran. Helped with technical procedures. \\ ${ }^{v}$ Assistant Professor, Faculty of Experimental Science, Kahnooj Branch, Islamic Azad University, Kerman, Iran. Analysis of data, manuscript writing. \\ ${ }^{\mathrm{V}}$ Young Researchers and Elite Club, Kahnooj Branch, Islamic Azad University, Kerman, Iran. Processing of study information.
}

\section{ABSTRACT}

PURPOSE: Articular Cartilage has limited potential for self-repair and tissue engineering approaches attempt to repair articular cartilage by scaffolds. We hypothesized that the combined hydroxyapatite and zirconia stabilized yttria would enhance the quality of cartilage healing.

METHODS: In ten New Zealand white rabbits bilateral full-thickness osteochondral defect, $4 \mathrm{~mm}$ in diameter and $3 \mathrm{~mm}$ depth, was created on the articular cartilage of the patellar groove of the distal femur. In group I the scaffold was implanted into the right stifle and the same defect was created in the left stifle without any transplant (group II). Specimens were harvested at 12 weeks after implantation, examined histologically for morphologic features, and stained immunohistochemically for type-II collagen.

RESULTS: In group I the defect was filled with a white translucent cartilage tissue In contrast, the defects in the group II remained almost empty. In the group I, the defects were mostly filled with hyaline-like cartilage evidenced but defects in group II were filled with fibrous tissue with surface irregularities. Positive immunohistochemical staining of type-II collagen was observed in group I and it was absent in the control group.

CONCLUSION: The hydroxyapatite/yttria stabilized zirconia scaffold would be an effective scaffold for cartilage tissue engineering. Key words: Nanostructures. Hydroxyapatites. Cartilage, Articular. Rabbits. 


\section{Introduction}

Healing of cartilage injuries of the joints remains a difficult problem in orthopedic surgery. Because of its avascular tissue with a low level of mitotic cellular activity, articular cartilage defects have a poor capacity for repair ${ }^{1}$.

Cartilage injuries of the joints leading to osteochondral defects are exceedingly common ${ }^{2}$.

Several clinical methods have been used to repair cartilage lesions, including microfracture, mosaicplasty, and cell-based therapies ${ }^{3}$. However, these methods have not always provided satisfactory results ${ }^{4,5}$. Tissue engineering presents a potentially effective method of treating cartilage damage ${ }^{6}$.

Matrix-based tissue-engineering approaches aim to use structural implants and/or materials to replace the defects ${ }^{7,8}$. Scaffolds can act as a three-dimensional structure for tissue regeneration that might mimic the native tissue properties as well as accelerate restoration of tissue function ${ }^{9}$. Various types of scaffolds made of nondegradable or biodegradable, synthetic and natural polymers have been found to provide a favorable environment for cartilage lesions ${ }^{10-12}$. Hydroxyapatite $\left(\mathrm{Ca}_{10}\left(\mathrm{PO}_{4}\right)_{6}(\mathrm{OH})_{2}\right)$ is one of the implants materials with medical applications due to its higher biocompatibility ${ }^{13,14}$. It seems to be the most appropriate ceramic material for cartilage tissue engineering. However, the low strength and fracture toughness of the material have reduced the field of possible applications ${ }^{15,16}$.

The hydroxyapatite found complete utilization after proper preparation of composite. Zirconium dioxide of $\left(\mathrm{ZrO}_{2}\right)$ is used in reinforcing phases based on its good toughness ${ }^{17}$. When zirconia's is use to reinforce hydroxyapatite composite, the properties of both materials are combined advantageously ${ }^{18,19}$.

A combination of material properties (i.e., the bioactivity of hydroxyapatite and the high strength of zirconia) should yield bioactive implant materials with improved mechanical properties ${ }^{20}$

Therefore, in this study, we hypothesized that the combined delivery of hydroxyapatite and zirconia stabilized yttria (HZY) would enhance the quality of new cartilage formation in a rabbit osteochondral defect model.

\section{Methods}

\section{Surgical procedures}

All animal experiments were conducted according to the guidelines provided by the animal committee of the Kahnooj University and was carried out in accordance with Guidelines for the care and use of Laboratory Animals. Ten skeletally mature male New Zealand white rabbits weighing 2.7-3.5 kg were used. The animals were anesthetized by intramuscular administration of medetomidine hydrochloride $(0.5 \mathrm{mg} / \mathrm{kg})$ and ketamine hydrochloride $(25 \mathrm{mg} / \mathrm{kg})$.

Under sterile conditions a medial parapatellar skin incision, the patella was dislocated laterally. Bilateral fullthickness cylindrical osteochondral defect, $4 \mathrm{~mm}$ in diameter and $3 \mathrm{~mm}$ depth, was created on the articular cartilage of the patellar groove of the distal femur using a drill-bit with continuous saline irrigation (Figure 1A). After all debris was removed by flushing with saline, the implants were transplanted (Figure 1B).

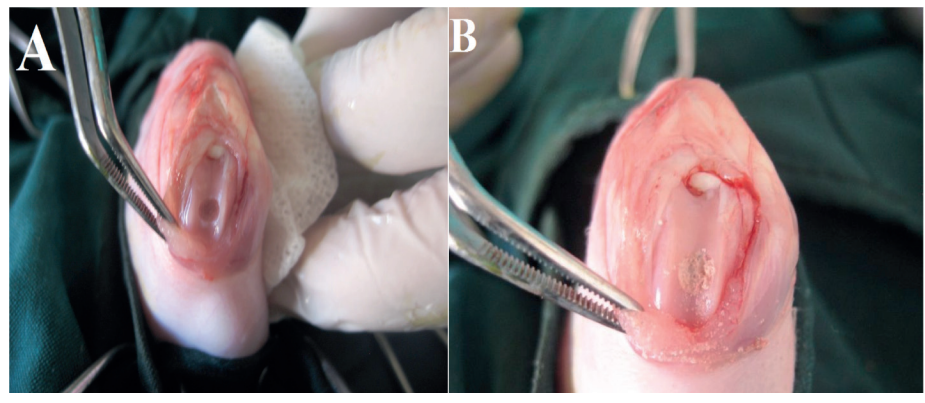

FIGURE 1 - Surgical procedures: (A) Macroscopic observation of an osteochondral defect in the patellar groove of the distal femur; (B) HZY scaffold was placed at the defect.

The nanostructured HZY were prepared by a sol-gel method according to a previous report by Salehi et al. ${ }^{21}$. In group I the HZY scaffold was implanted into the right stifle. As the negative control, the same defect was created in the left stifle without any transplant (group II). The joint capsule, the fascial layer, and the skin were closed. After the operation, the animals were returned to their cages after surgery and allowed to move freely. Animals were sacrificed with an overdose of sodium pentobarbital at 12 weeks after the operation.

\section{Gross examination}

Distal femurs were harvested at 12 weeks. The knee was assessed for adhesions, osteoarthritic changes, and synovitis. The appearance of the restored cartilage in terms of color, integrity, and smoothness was examined. The distal femurs were resected and photographed then were fixed in $10 \%$ buffered formalin $(\mathrm{pH}$ 7.4) for one week.

\section{Histological examination}

The specimens were decalcified in $20 \%$ 
ethylenediaminetetraacetic acid solution (Decal Corporation, Congers, NY, and USA) for two weeks, dehydrated through a graded series of ethanol, and then embedded in paraffin. Sections of $5 \mathrm{~mm}$ thickness were cut sagittally through the center of the defect site and were stained with hematoxylin and eosin or else were used for immunohistochemical examination.

For analysis of the repaired tissue, histological sections were scored blindly by an expert observer according to a modified version of the histological grading scale, as described by Wakitani et al. $^{22}$.

\section{Immunohistochemical examination}

Sections were deparaffinized using xylene and then dehydrated through graded alcohols and rinsed three times with PBS. For antigen retrieval, the sections were pretreated with $1 \%$ bovine serum albumin for 30 min to block any non-specific reaction. Type-II collagen was immunolocalized with a mouse antibody to mouse anti-human type-II collagen (1:100; Daiichi Fine Chemical). After incubation overnight with the primary antibody at $48^{\circ} \mathrm{C}$, sections were rinsed five times in PBS and then incubated with biotinylated anti-mouse Ig for secondary antibody. They were rinsed three times with PBS, and treated for 60 min with streptavidin solution (Dako). Visualization was performed with diaminobenzidine and counterstaining with Mayer's hematoxylin. For negative controls, the primary antibody was omitted according to the immunohistochemical protocol.

\section{Statistical analysis}

The data were analyzed using SPSS (Ver. 16). We used the Mann-Whitney $U$-test for comparing mean scores in two groups.

\section{Results}

Figure 2 depicts a SEM micrograph of HZY powder, whose morphology is characterized by agglomerated nanoparticles with sizes smaller than $100 \mathrm{~nm}$.

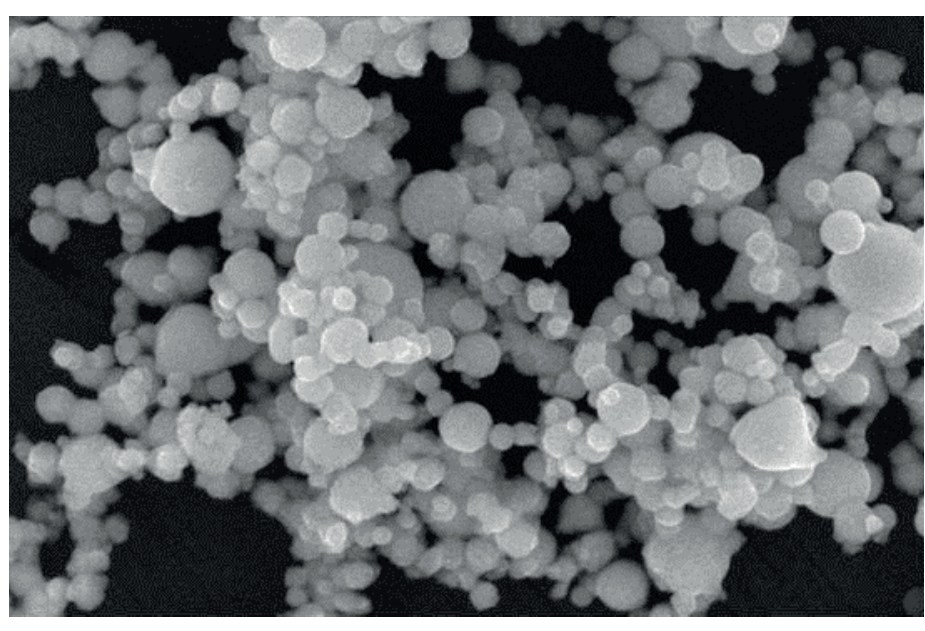

FIGURE 2 - SEM micrographs HZY structure.

\section{Macroscopic observation}

All animals exhibited normal movement during the 12 week period. No gross signs of infection, osteoarthritic change, or obvious synovitis were found in any rabbits.

In group I the defect was filled with a white translucent cartilage tissue However, The regenerative areas were clearly distinguishable from the normal cartilage. As well, a slightly rough surface remained at the center of grafted area (Figure $3 \mathrm{~A}$ ).

In contrast, the defects in the control group remained almost empty, and the bottoms of the defects were covered with reddish granulated tissue. Irregular tissue with depression was noted and the margin of the defect was clearly differentiated from surrounding normal cartilage (Figure 3B).

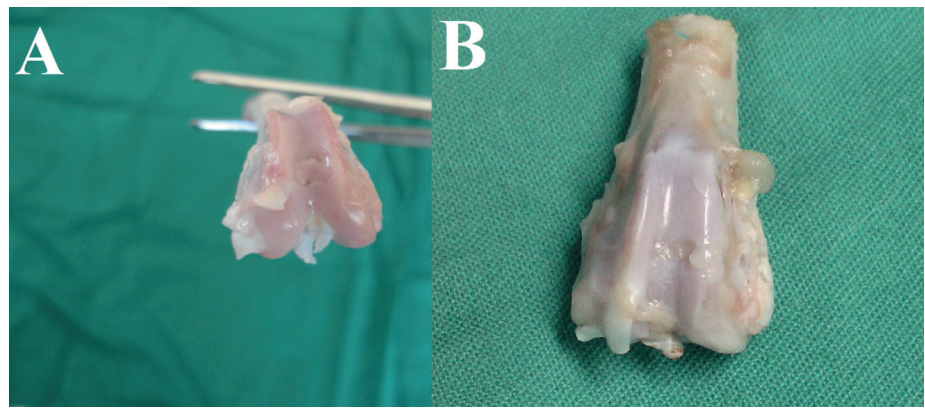

FIGURE 3 - Macroscopic evaluation of defects on the patellar groove of the distal femur 12 weeks after surgery. (A) In group I, defect site has more than a $90 \%$ filled with smooth translucent cartilage tissue which appeared differentiable from the surrounding normal cartilage. (B) In group II, The regenerated area showed incomplete defect repair with newly formed fibrous tissue.

\section{Histological observations}

In the group I, the defects were mostly filled with hyalinelike cartilage evidenced by an intense H\&E staining as shown in 
Figure 4A. The subchondral areas of the defects were regenerated with new bone. Notably, most of the implants persisted. In the subchondral region, although remaining HZY was still observed in some sections.

Newly formed cartilage tissue on the surface had an appearance of hyaline cartilage that was not well-integrated with the native cartilage and an observer could still distinguish the repaired tissue from surrounding normal cartilage.

The defects in the control group were filled with fibrous tissue with surface irregularities; the cartilaginous extracellular matrix was very poorly developed (Figure 4B).

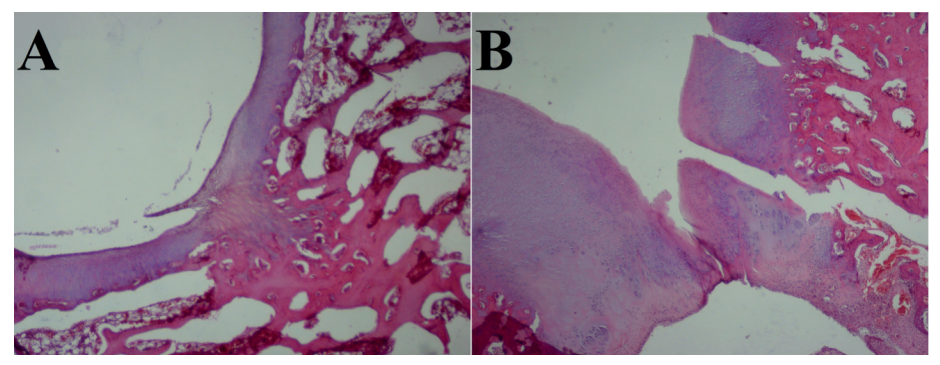

FIGURE 4 - Histology of the defect site at 12 weeks after surgery. (A) In group I, The subchondral areas of the defects were regenerated with new bone; however, the borderline was still recognizable. (B) In the control group fibrous tissue was filled the defect site with surface irregularities. $\mathrm{N}$ : Normal cartilage; SCB: subchondral bone (H\&E stain, Scale bar = $10.0 \mu \mathrm{m}$.).

Detailed results of microscopic evaluations are summarized in Table 1.

TABLE 1 - Cartilage repair histological scores

\section{Group}

I

II

\begin{tabular}{ccccccc}
\hline $\begin{array}{c}\text { Characteristic } \\
\text { (maximum score) }\end{array}$ & Mean & $\mathrm{N}(\mathrm{n}=10)$ & $\mathrm{SD}$ & Mean & $\mathrm{N}(\mathrm{n}=10)$ & $\mathrm{SD}$ \\
$\begin{array}{c}\text { Cell morphology (4) } \\
\begin{array}{c}\text { Metachromasia of } \\
\text { matrix (3) }\end{array}\end{array}$ & 2.1 & 10 & 0.4 & 1.5 & 10 & 0.5 \\
$\quad \begin{array}{c}\text { Surface } \\
\text { characteristics (3) }\end{array}$ & 1.1 & 10 & 0.4 & 0.8 & 10 & 0.5 \\
$\begin{array}{c}\text { Cartilage thickness } \\
\quad(2)\end{array}$ & 1 & 10 & 0 & 0.7 & 10 & 0.3 \\
$\begin{array}{c}\text { Binding to articular } \\
\text { cartilage (2) }\end{array}$ & 1.9 & 10 & 0.3 & 1.1 & 10 & 0.1 \\
$\begin{array}{c}\text { Reconstruction of } \\
\text { subchondral layer (4) }\end{array}$ & 3.3 & 10 & 0.1 & 1.7 & 10 & 0.3 \\
$\quad$ Total (18) & $11.5 *$ & 10 & 1.4 & 7.9 & 10 & 2 \\
\hline
\end{tabular}

*group I is significantly different from group II, $\mathrm{p}<0.05$.

\section{Immunohistochemical analysis}

In group I, positive immunohistochemical staining of type-II collagen was observed and it was mainly localized in the matrix around the lacunae in the regenerated cartilage. There was no immunoreactivity detected in fibrous reparative tissue formed in the control group (Figure 5).

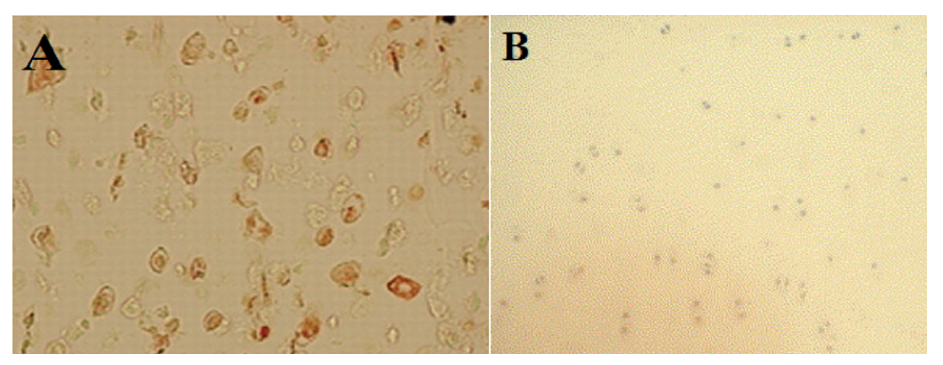

FIGURE 5 - Immunohistochemical staining for type II collagen. Collagen type II staining was positive in group I (A), but was absent in control group (B).

\section{Discussion}

Articular Cartilage has limited potential for self-repair and cartilage repair remains a problem in tissue engineering ${ }^{23,24}$. Tissue engineering approaches attempt to repair articular cartilage by scaffolds. Scaffolds represent the basic structure of the engineered tissue and establish an environment for neoextracellular matrix synthesis. They can be associated to signals to modulate cell activity ${ }^{25}$. Scaffolds are central components of many tissue engineering strategies. Various scaffold materials have been tested, including both naturally derived and synthetic materials ${ }^{22}$.

The hydroxyapatite is used as implant material in medicine. It is well known that probability law governs ceramics mechanical properties and the mathematical strength should be assumed as a random variable ${ }^{13}$.

Many techniques have been suggested for the manufacture of hydroxyapatite hybrid scaffold that lead to prepare various types of hydroxyapatite scaffolds, such as collagen sponge incorporating a hydroxyapatite/ chondroitinsulfate, hydroxyapatite forsterite bioglass ${ }^{26}$, porous poly (lactide-co-glycolide)/nanohydroxyapatite ${ }^{27}$. Nano-hydroxyapatite reinforced poly (vinyl alcohol) gel ${ }^{28}$ and Poly-1-Lactic Acid/Hydroxyapatite Electrospun Nanocomposites ${ }^{29}$.

Nano hydroxyapatite-zirconia showed a good histocompatibility. It has a broad prospect as a biomaterial scaffold for tissue engineering ${ }^{30}$. The addition of $\mathrm{ZrO} 2$ particles to the hydroxyapatite coating has received considerable attention 
because $\mathrm{ZrO}_{2}$ particles increase the bonding strength between hydroxyapatite coating and substrate ${ }^{31}$. In this study, nanostructured hydroxyapatite/yttria stabilized zirconia coatings were prepared by a sol-gel method.

Previous reports suggested that cartilage fibrillation would proceed when immature surface cartilage lost sufficient mechanical support during the degradation of the scaffold ${ }^{1}$. Subchondral bone formation may have resulted from subchondral bone repair induced by the osteoconductive property of HZY. The results of the present study showed that the HZY scaffold provides a favorable environment for formation of hyaline-appearing repair tissues sustained over 12 weeks. The implants were well tolerated by surrounding tissues, and reabsorbed with no side-effects upon the remodeling.

HZY were found to be partially degraded and newly formed tissue filling was observed within defects. Although scaffold degradation rate slightly varied among the animals, no signs of prolonged inflammatory response, osteoarthritis or cartilage destruction were observed, which demonstrated the biocompatibility of HZY and their degradation products ${ }^{1}$. As shown in figure 4 hyaline cartilage with well-organized chondrocytes were seen to fill the chondral portion of the defect at 12 weeks.

Ito et $a l .{ }^{32}$ evaluated the porous calcium hydroxyapatite ceramics to treat osteochondral defects and they reported the defects were repaired with cartilage-like tissue with good subchondral bone formation histologically. In this study the smoother articular surface observed in the HZY group may be due to the faster subchondral bone formation in this group which provided sufficient mechanical support for the articular surface.

The capacity of the hydroxyapatite with biodegradable polymer (poly-d,l-lactic acid/polyethylene glycol) were evaluated to induce the regeneration of articular cartilage. It promotes the repair of full-thickness articular cartilage defects within as short a period as three weeks in the rabbit model ${ }^{23}$. Depending on the results of these studies, it may be possible to develop acellular treatments for cartilage articular defects by using the HZY as a scaffold.

In some researches hydroxyapatite combined with Collagen, poly-d, l-lactic acid/polyethylene glycol $^{23}$, poly (lactide-co-glycolide) and polyglycolic acid for cartilage tissue engineering and all results showed facilitation of articular cartilage regeneration ${ }^{33}$. This was confirmed by the results of the present study. Further studies, including evaluation of the mechanical properties of regenerated cartilage and the responses of different animals are necessary.

\section{Conclusion}

The hydroxyapatite/yttria stabilized zirconia scaffold would be an effective scaffold for cartilage tissue engineering.

\section{References}

1. Mandelbaum BR, Browne JE, Freddie F. Articular cartilage lesions of the knee. Am J Sports Med. 1998;26:853-61.

2. Dan Qu, Jihua Li, Yubao Li, Ashish Khadka, Yi Zuo, Hang Wang, Yiming Liu, Lin Cheng. Ectopic osteochondral formation of biomimetic porous PVA-n-HA/PA6 bilayered scaffold and BMSCs construct in rabbit. J Biomed Mater Res B Appl Biomater. 2011;96B(1):9-15.

3. Maehara H, Sotome S, Yoshii T, Torigoe I, Kawasaki Y, Sugata Y, Yuasa M, Hirano M, Mochizuki N, Kikuchi M, Shinomiya K, Okawal A. Repair of large osteochondral defects in rabbits using porous hydroxyapatite/collagen $(\mathrm{HAp} / \mathrm{Col})$ and fibroblast growth factor-2 (FGF-2). J Orthop Res. 2010;677-86.

4. Temenoff JS, Mikos AG. Review: tissue engineering for regeneration of articular cartilage. Biomaterials. 2000;21:431-40.

5. Smith GD, Knutsen G, Richardson JB. A clinical review of cartilage repair techniques. J Bone Joint Surg Br. 2005 87(4):445-9.

6. Lum L, Elisseeff J. Injectable hydrogels for cartilage. Topics in tissue engineering (eds). N. Tissue Engineering Ashammakhi \& P. Ferretti; 2003.

7. Balcik C, Tokdemir T, Enköylü AS, Koc N, Timuc M, Akin S, Korkusuz P, Korkusuz F. Early weight bearing of porous HA/TCP $(60 / 40)$ ceramics in vivo: a longitudinal study in a segmental bone defect model of rabbit. Acta Biomater. 2007;3(6):985-96.

8. Jackson DW, Simon TM. Tissue engineering principles in orthopaedic surgery. Clin Orthop. 1999;367(Suppl.):31-45.

9. O'Shea TM, Miao X. Bilayered scaffolds for osteochondral tissue engineering. Tissue Eng Part B Rev. 2008;14:447-64.

10. Lu L, Zhu X, Valenzuela RG, Currier BL, Yaszemski MJ. Biodegradable polymer scaffolds for cartilage tissue engineering. Clin Orthop Relat Res. 2001;S251-70.

11. Cao T, Ho KH, Teoh SH. Scaffold design and in vitro study of osteochondral coculture in a three-dimensional porous polycaprolactone scaffold fabricated by fused deposition modeling. Tissue Eng. 2003;9:103-12.

12. Chung C, Burdick JA. Engineering cartilage tissue. Adv Drug Deliv Rev. 2008;60:243-62.

13. Bolboaca SD, Jantschi L. Similarities analysis on hydroxyapatitezirconia composites. Leonardo J Sci. 2000;153-64.

14. Kon E, Muraglia A, Corsi A, Bianco P, Marcacci M, Martin I, Boyde A, Ruspantini I, Chistolini P, Rocca M, Giardino R, Cancedda R, Quarto R. Autologous bone marrow stromal cells loaded onto porous hydroxyapatite ceramic accelerate bone repair in critical-size defects of sheep long bones. J Biomed Mater Res. 2000;49(3):32837.

15. With GD, Van Dijk HJA, Hattu N, Prijs K. Preparation, microstructure and mechanical properties of dense polycrystalline hydroxyapatite. J Mater Sci. 1981;16:1592.

16. Hench LL. Bioceramics. J Am Ceram Soc. 1998;81(7):1705.

17. Li J, Hermansson L, Soremark R. High-strength biofunctional zirconia: mechanical properties and static fatigue behavior of zirconia-apatite composites. J Mater Sci Mater Med. 1993;4:50-4.

18. Piconi C, Maccauro G. Zirconia as a ceramic biomaterial. Biomaterials. 1999;20:1-25. 
19. Shen Z, Adolfsson E, Nygren M, Gao L, Kawaoka H, Niihara K. Dense hydroxyapatit-zirconia ceramic composit with high strength for biological application. Adv Mater. 2001;13:214-6.

20. Prabakaran K, Kannan S, Rajeswari S. Development and characterisation of zirconia and hydroxyapatite composites for orthopaedic applications. Trends Biomater Artif Organs. 2005;18 (2):114-6.

21. Salehi S, Fathi MH. Fabrication and characterization of sol-gel derived hydroxyapatite/zirconia composite nanopowders with various yttria contents. Ceramics Int. 2010;36(5):1659-67.

22. Abedi G, Sotoudeh A, Soleymani M, Shafiee A, Mortazavi P, Aflatoonian MR. Collagen-poly(vinyl alcohol) nanofiber scaffold for cartilage repair. J Biomaterials Sci. 2011;22:2445-55.

23. Tamai N, Myoui A, Hirao M, Kaito T, Ochi T, Tanaka J, Takaoka $\mathrm{K}$, Yoshikawa H. A new biotechnology for articular cartilage repair: subchondral implantation of a composite of interconnected porous hydroxyapatite, synthetic polymer (PLA-PEG), and bone morphogenetic protein-2 (rhBMP-2). Osteoarthritis Cartilage. 2005;13(5):405-17.

24. Yohimi O, Takuro A, Tomohiko Y, Toshiyuki I, Kazu S, Toshimasa U, Junzo T. A collagen sponge incorporating a hydroxyapatite/ chondroitinsulfate composite as a scaffold for cartilage tissue engineering. J Biomaterials Sci Polymer Edition. 2009;20(13):186174.

25. Kitahara S, Nakagawa K, Sah RL, Wada Y, Ogawa T, Moriya $\mathrm{H}$, Masuda K. In vivo maturation of scaffold-free engineered articular cartilage on hydroxyapatite. Tissue Engineering Part A. 2008;14(11):1905-13.

26. Sebdani MM, Fathi MH. Novel hydroxyapatite-forsterite-bioglass nanocomposite coatings with improved mechanical properties. J Alloys Compounds. 2011;509(5):2273-6.

27. Xue D, Zheng Q, Zong C, Li Q, Li H, Qian S, Zhang B, Yu L, Pan Z. Osteochondral repair using porous poly (lactide-co-glycolide)/nanohydroxyapatite hybrid scaffolds with undifferentiated mesenchymal stem cells in a rat model. J Biomed Mater Res A. 2010;94(1):25970.

28. Pan Y, Xiong D. Friction properties of nano-hydroxyapatite reinforced poly (vinyl alcohol) gel composites as an articular cartilage. Wear. 2009;266(25):699-703.

29. Spadaccio C, Rainer A, Trombetta M, Vadalá G, Chello M, Covino E, Denaro V, Toyoda Y, Jorge A. Genovese. Poly-L-lactic acid/ hydroxyapatite electrospun nanocomposites induce chondrogenic differentiation of human MSC. Ann Biomed Eng. 2009;37(7):137689.

30. Chao L, ShuGing T, Lin ZC. Histocompatibility evaluation of nano hydroxyapatite $-40 \%$ zirconia composite bioceramic. Orth J China. 2009;17-23.

31. Salehi S, Fathi MH. Fabrication and characterization of sol-gel derived hydroxyapatite/zirconia composite nanopowders with various yttria contents. Ceramics Int. 2010;36 (5):1659-67.

32. Ito Y, Adachi N, Nakamae A, Yanada S, Ochi M. Transplantation of tissue-engineered osteochondral plug using cultured chondrocytes and interconnected porous calcium hydroxyapatite ceramic cylindrical plugs to treat osteochondral defects in a rabbit model. Artif Organs. 2008;32(1):36-44.

33. Zhou XZ, Leung VY, Dong QR, Cheung KM, Chan D, Lu WW. Mesenchymal stem cell-based repair of articular cartilage with polyglycolic acid-hydroxyapatite biphasic scaffold. Int J Artif Organs. 2008;31(6):480-9.

\section{Correspondence:}

Amir Sotoudeh

Islamic Azad University

Kahnooj Branch

Kahnooj, Iran

Phone: 00989121768066

Fax: 00983495230203

dramirsotoudeh@kahnoojiau.ac.ir

Received: January 24, 2013

Review: March 21, 2013

Accepted: April 22, 2013

Conflict of interest: none

Financial source: Islamic Azad University

${ }^{1}$ Research performed at Department of Experimental Surgery, Faculty of Veterinary, Islamic Azad University (IAU), Kahnooj Branch. 